\title{
Specific detection of Candida albicans and Candida tropicalis by fluorescent in situ hybridization with an 185 rRNA-targeted oligonucleotide probe
}

\author{
Axel Lischewski, ${ }^{1}$ Rudolf I. Amann, ${ }^{2}$ Dag Harmsen, ${ }^{3}$ Hilde Merkert, ${ }^{4}$ \\ Jörg Hacker ${ }^{1,4}$ and Joachim Morschhäuser ${ }^{1}$
}

Author for correspondence: Joachim Morschhäuser. Tel: +499313126 47. Fax: +49931 571954.
e-mail: j.morschhaeuser@ rzbox.uni-wuerzburg.de

\footnotetext{
1 Zentrum für

Infektionsforschung,

Universităt Würzburg,

Rontgenring 11, D-97070

Würzburg, Germany

2 Lehrstuhl für

Mikrobiologie, Technische

Universităt München,

Arcisstraße 16, D-80290

München, Germany

3 Institut für Hygiene und Mikrobiologie, Universităt Würzburg, Josef-

Schneider-Straße 2, Bau

17, D-97080 Würzurg,

Germany

4 Institut fur Molekulare Infektionsbiologie, Universităt Würzburg, Röntgenring 11, D-97070

Würzburg, Germany
}

\begin{abstract}
In situ hybridization of whole cells with rRNA-targeted, fluorescently labelled oligonucleotide probes is a powerful method to specifically detect microorganisms in their natural habitat without cultivation and subsequent identification by phenotypic characterization. To examine the use of this method for the specific detection of pathogenic Candida species, we have designed an oligonucleotide probe which binds to the 185 rRNA of $C$. albicans and C. tropicalis, the two most important pathogenic Candida species, and differentiates them from other clinically relevant species. After establishing suitable hybridization conditions, we confirmed the specificity of our probe 020 in RNA dot blot hybridizations with a series of reference strains and clinical isolates of medically important Candida species. All C. albicans and C. tropicalis strains hybridized with the probe, whereas all strains of $C$. parapsilosis, C. glabrata, C. krusei, C. guilliermondii, C. kefyr and C. lusitaniae did not. When we used the fluorescently labelled probe 020 to specifically detect single cells of the two target species by in situ hybridization, both $\mathrm{C}$. albicans and $C$. tropicalis reacted strongly with the probe and could be clearly differentiated from C. krusei and C. parapsilosis, although the latter organism contains only two nucleotide mismatches in the probe target region. This discrimination capacity was also seen when mixed suspensions of $C$. albicans and $C$. parapsilosis were hybridized with the probe. After infection of a human endothelial cell line with $C$. albicans and $C$. krusei, $C$. albicans cells adhering to the endothelial cells were easily distinguishable from the $C$. krusei cells by fluorescent in situ hybridization with probe 020 . In addition, germ tubes and hyphae of $\mathrm{C}$. albicans were also efficiently labelled. The application of fluorescently labelled rRNA-targeted oligonucleotide probes therefore appears to be a valuable tool for the specific detection and identification of different members of the genus Candida, which does not require any cultivation.
\end{abstract}

Keywords: Candida, 18S rRNA, oligonucleotide probe, fluorescence, in situ hybridization

\section{INTRODUCTION}

The opportunistic fungal pathogen Candida albicans and other species of the genus Candida are able to cause superficial and disseminated infections in immunocompromised patients. As Candida species differ in their

Abbreviation: FLUOS, 5(6)-carboxyfluorescein- $N$-hydroxysuccinimide ester. susceptibility to widely utilized systemic antifungal agents, such as azoles (Rex et al., 1995), identification of the infecting species is important to ensure effective therapy strategies. The diagnosis of systemic Candida infections is a major problem because the clinical presentation is usually non-specific (Jones, 1990). Disseminated candidiasis is in most cases diagnosed by positive blood culture. However, blood cultures from patients with histologically proven disseminated candi- 
diasis are often negative. In addition, even with an optimal blood culture system like the lysis centrifugation method, it takes a minimum of $2 \mathrm{~d}$ for detection and even longer for species identification (Jones, 1990). To reduce mortality in patients suffering from invasive candidiasis, however, early initiation of proper antifungal drug therapy is critical (Anaissie, 1992; Fraser et al., 1992).

Direct histologic detection of the fungus in biopsy material from deep tissue offers the best diagnostic assurance and eliminates the need for culture. The infecting species, however, can not solely be identified by microscopic examination, and Candida pseudohyphae may even be erroneously diagnosed as Aspergillus hyphae, for example in liver biopsy (Kwon-Chung \& Bennett, 1992). Other non-culture methods for the detection of Candida infections, such as measurement of serum D-arabinitol, detection of specific antigens or antibodies, or amplification of fungal DNA from blood and urine by PCR, have also been developed, but their diagnostic value is doubtful or, for the latter, remains to be established (for a review, see Reiss \& Morrisson, 1993).

Fluorescent in situ hybridization of whole cells with rRNA-targeted oligonucleotide probes has become a highly valuable tool for the specific detection of microorganisms without cultivation (DeLong et al., 1989; Amann et al., 1995). Non-culturable bacteria have been identified in their natural environment, e.g. in activated sludge, in the mammalian gut, or as endosymbionts (Amann et al., 1991; Poulsen et al., 1994; Wagner et al., 1994). The use of rRNA as the target for hybridization has several advantages. Firstly, the sequence of the rRNA, especially the small subunit (ss) rRNA, is known for many organisms and consists of evolutionarily more or less conserved regions. Consequently, target sites can be selected that are specific for a certain species or for groups of related organisms. Secondly, the target molecule is abundant in the cells, resulting in a strong hybridization signal that enables the detection of single cells. Thirdly, in contrast to immunological methods that rely on the expression of specific markers, which may not be constant, phenotypic variation does not pose a problem when rRNA is used as the target. For these reasons, we intended to establish the method of fluorescent in situ hybridization for the specific detection of Candida species. One aim was to design a probe that detects $C$. albicans, the most important pathogenic species. To examine whether this technique is generally applicable for other Candida species, we chose a target region that is identical in C. albicans and C. tropicalis but different in other clinically important Candida species. Our results demonstrate that fluorescently labelled, rRNA-targeted oligonucleotide probes can be used to specifically detect Candida species by in situ hybridization.

\section{METHODS}

Strain maintenance and culture conditions. All fungal strains used in this study are listed in Table 1. Candida reference strains were obtained from the American Type Culture Collection (ATCC; Rockville, MD, USA), from the Deutsche Sammlung für Mikroorganismen und Zellkulturen (DSM, Braunschweig,
Table 1. Fungal strains used in this study

\begin{tabular}{|c|c|c|}
\hline Strain no. & Species & Strain \\
\hline 1 & C. albicans & ATCC 44808 \\
\hline 2 & C. albicans & ATCC 44807 \\
\hline 3 & C. albicans & ATCC 38696 \\
\hline 4 & C. albicans & DSM 1386 \\
\hline 5 & C. albicans & CBS 562 \\
\hline 6 & C. albicans & CBS 5983 \\
\hline 7 & C. albicans & Clinical isolate 95 \\
\hline 8 & C. albicans & Clinical isolate 99 \\
\hline 9 & C. albicans & Clinical isolate 100 \\
\hline 10 & C. albicans & Clinical isolate 101 \\
\hline 11 & C. albicans & Clinical isolate 102 \\
\hline 12 & C. albicans & Clinical isolate 103 \\
\hline 13 & C. albicans & Clinical isolate 104 \\
\hline 14 & C. albicans & Clinical isolate 105 \\
\hline 15 & C. albicans & Clinical isolate 106 \\
\hline 16 & C. albicans & Clinical isolate 107 \\
\hline 17 & C. tropicalis & DSM 4238 \\
\hline 18 & C. tropicalis & Clinical isolate GR1 \\
\hline 19 & C. tropicalis & Clinical isolate GR2 \\
\hline 20 & C. tropicalis & Clinical isolate GR3 \\
\hline 21 & C. tropicalis & Clinical isolate GR4 \\
\hline 22 & C. parapsilosis & DSM 70126 \\
\hline 23 & C. parapsilosis & Clinical isolate GR33 \\
\hline 24 & C. parapsilosis & Clinical isolate GR34 \\
\hline 25 & C. parapsilosis & Clinical isolate GR36 \\
\hline 26 & C. glabrata & DSM 70614 \\
\hline 27 & C. glabrata & Clinical isolate GR10 \\
\hline 28 & C. glabrata & Clinical isolate GR11 \\
\hline 29 & C. glabrata & Clinical isolate GR12 \\
\hline 30 & C. glabrata & Clinical isolate GR13 \\
\hline 31 & C. krusei & DSM 70079 \\
\hline 32 & C. krusei & Clinical isolate GR20 \\
\hline 33 & C. krusei & Clinical isolate GR21 \\
\hline 34 & C. krusei & Clinical isolate GR22 \\
\hline 35 & C. krusei & Clinical isolate GR23 \\
\hline 36 & C. guilliermondii & Clinical isolate GR30 \\
\hline 37 & C. guilliermondii & Clinical isolate GR31 \\
\hline 38 & C. guilliermondii & Clinical isolate GR32 \\
\hline 39 & C. keffr & Clinical isolate GR38 \\
\hline 40 & C. keffyr & Clinical isolate GR39 \\
\hline 41 & C. kefyr & Clinical isolate GR40 \\
\hline 42 & C. keffyr & Clinical isolate GR41 \\
\hline 43 & C. lusitaniae & Clinical isolate GR42 \\
\hline 44 & C. Iusitaniae & Clinical isolate GR43 \\
\hline 45 & C. Iusitaniae & Clinical isolate GR44 \\
\hline 46 & C. Iusitaniae & Clinical isolate GR45 \\
\hline 47 & S. cerevisiae & Clinical isolate \\
\hline
\end{tabular}

Germany) and from the Central Bureau voor Schimmelcultures (CBS, Baarn, The Netherlands). Clinical isolates were obtained from various hospitals in Greifswald as well as Würzburg, Germany, and were identified using the Vitek Automated Microbiology System (Vitek Systems Inc.). The identity of $C$. albicans isolates was also confirmed by a positive germ tube test. Immediately upon arrival, the strains were stored at $-80^{\circ} \mathrm{C}$ in Sabouraud medium $(4 \%, \mathrm{w} / \mathrm{v}$, glucose, $1 \%, \mathrm{w} / \mathrm{v}$, peptone), 
containing $15 \%(\mathrm{v} / \mathrm{v})$ glycerol. Strains were cultured on Sabouraud plates, containing $1.5 \%(\mathrm{w} / \mathrm{v})$ agar at $30^{\circ} \mathrm{C}$ for $1-2 \mathrm{~d}$ and then stored at $4{ }^{\circ} \mathrm{C}$.

Oligonucleotide probes and fluorescence dye labelling. The oligonucleotides used in this study were synthesized by MWG Biotech, Munich, Germany. Oligonucleotide O20 (5' CCCCCTTTCCTAAACCAATCCGGA $3^{\prime}$ ) is complementary to a sequence in the $C$. albicans ss rRNA corresponding to positions 1674-1697 of the Saccharomyces cerevisiae 18S rRNA (Mankin et al., 1986, see Results). Oligonucleotide EUK516 (5' ACCAGACTTGCCCTCC 3') is complementary to positions $548-563$ of the $S$. cerevisiae $18 \mathrm{~S} \mathrm{rRA}$, a sequence which is identical in all eukaryotic organisms (Amann et al., 1990a). For in situ hybridization, the oligonucleotide $\mathrm{O} 20$ was coupled with a C6TFA aminolinker [6-(trifluoroacetylamino)-hexyl-(2-cyanoethyl)-( $N, N$-diisopropyl)-phosphoramidite] at the $5^{\prime}$ end (MWG Biotech). Subsequent labelling with 5(6)-carboxyfluorescein- $N$-hydroxysuccinimide ester (FLUOS, Boehringer Mannheim) was carried out as described previously (Manz et al., 1992). The labelled probe was purified by exclusion chromatography, PAGE and reversed-phase chromatography as described by Amann et al. (1990b) and stored at $-20^{\circ} \mathrm{C}$.

RNA extraction and dot blot hybridization. Total RNA was extracted from Candida strains grown to exponential phase in Sabouraud medium at $30^{\circ} \mathrm{C}$, by the hot acidic phenol method (Golemis et al., 1993). After spectrophotometric quantification, the quality of the RNA was controlled by agarose gel electrophoresis and staining with ethidium bromide. RNA samples were stored at $-20^{\circ} \mathrm{C}$. For dot blot hybridization experiments, $10 \mu \mathrm{g}$ RNA of each strain were transferred onto a Biodyne $\mathrm{B}$ nylon membrane, using a minifold I dot blot apparatus (Schleicher \& Schüll), and immobilized by UV treatment. Labelling of oligonucleotide probes with digoxigenin, hybridization, washing of the membranes and signal detection with the substrate 3-(4-methoxyspiro\{1,2-dioxetan$3,2^{\prime}$-(5'-chloro)tricyclo-[3.3.1.1 $\left.1^{3,7}\right]$ decan $\}-4$-yl)phenyl phosphate (CSPD) were performed using the $3^{\prime}$ oligonucleotide labelling and nucleic acid labelling kits provided by Boehringer Mannheim. The instructions of the manufacturer were modified as follows. Hybridization stringency was controlled by varying the formamide content of the hybridization buffer and/or the hybridization temperature (see Results). The relationship between hybridization temperature and formamide content of the buffer was calculated by assuming a decrease of about $0.7^{\circ} \mathrm{C}$ in hybridization temperature for every $1 \%$ increase in the concentration of formamide (McConaughy et al., 1969). Washing was performed at slightly elevated temperatures compared to hybridization $\left(4^{\circ} \mathrm{C}\right.$ increase for $\mathrm{O} 20,3{ }^{\circ} \mathrm{C}$ increase for EUK516). For rehybridization, filters were rinsed with water, treated twice with $0 \cdot 2 \mathrm{M} \mathrm{NaOH} / 0 \cdot 1 \%$ (w/v) SDS at $37^{\circ} \mathrm{C}$ for $15 \mathrm{~min}$ to remove the bound probe, and subsequently washed with $2 \times \mathrm{SSC}(300 \mathrm{mM} \mathrm{NaCl}, 30 \mathrm{mM} \mathrm{Na}$ citrate) .

In situ hybridization. Candida yeast cultures were grown in Sabouraud medium at $30^{\circ} \mathrm{C}$ to late exponential phase, harvested and washed with PBS ( $\mathrm{pH} 7 \cdot 2$ ). For preparing mixtures of $C$. albicans and $C$. parapsilosis, the cells were counted using a Neubauer haemocytometer, adjusted to equal density and mixed at different relative concentrations. To immobilize the cells on glass slides, $40 \mu \mathrm{l}$ of the cell suspensions was applied onto the slides and incubated for $1 \mathrm{~h}$ at room temperature. After washing with PBS ( $\mathrm{pH} 7 \cdot 2$ ), the cells were fixed for $20 \mathrm{~min}$ by adding $100 \%(\mathrm{v} / \mathrm{v})$ methanol, air-dried and dehydrated by subsequent immersion for $3 \mathrm{~min}$ each in 50, 80 and $96 \%(\mathrm{v} / \mathrm{v})$ ethanol.

The procedure for the in situ hybridization of whole cells with FLUOS-labelled oligonucleotide probes was described pre- viously (Manz et al., 1992) and was followed with minor modifications. Hybridization was performed at $43{ }^{\circ} \mathrm{C}$ using a formamide concentration of $45 \%(\mathrm{v} / \mathrm{v})$ in the hybridization buffer. Labelled O20 probe ( $50 \mathrm{ng}$ ) in $8 \mu$ l hybridization mix was applied per hybridization and the microscope slide was placed in a moisture chamber (Wilcox, 1993) to ensure a comparable vapour pressure. The slides were gently washed with water and immersed in a prewarmed washing solution $(40 \mathrm{mM} \mathrm{NaCl}$, $20 \mathrm{mM}$ Tris/ $\mathrm{HCl}, \mathrm{pH} 7 \cdot 5,0 \cdot 01 \%$ SDS, $5 \mathrm{mM}$ EDTA) at $45^{\circ} \mathrm{C}$ for $20 \mathrm{~min}$. The slides were rinsed with water, dried in a lighttight box and mounted with Citifluor. Fluorescence was detected using a Zeiss Axiolab microscope (Zeiss), equipped for epifluorescence microscopy with a $50 \mathrm{~W}$ mercury high pressure bulb and the Zeiss fluorescein-specific filter set 09 . Colour micrographs were taken on Fujichrome 400 or Agfachrome 100 slide film without any subsequent digital image processing. Exposure times were $0 \cdot 1-1 \cdot 5 \mathrm{~s}$ for phase contrast and 5-60 s for epifluorescence micrographs. The in situ hybridization experiments were carried out at least in duplicate to ensure reproducibility.

Induction of germ tubes and hyphae formation. C. albicans ATCC 44808 yeast cells were grown overnight in Soll's medium (Soll, 1986) at $25^{\circ} \mathrm{C}(\mathrm{pH} 4 \cdot 5)$. For hyphae induction, the cells were diluted $1: 10$ in Soll's medium ( $\mathrm{pH} \mathrm{6.8)}$ ) and incubated at $37^{\circ} \mathrm{C}$. After $2 \mathrm{~h}$ of incubation most cells had formed germ tubes, and after $4 \mathrm{~h}$ growth prolonged hyphae were visible. Germ tubes and hyphae were washed in PBS ( $\mathrm{pH} 7.2)$ and processed for in situ hybridization as described above.

Adherence assay. The human umbilical vein endothelial cell line EA.hy 926 (Edgell et al., 1983) was used in this study. The cells were cultured in RPMI 1640 tissue culture medium, containing $10 \%(\mathrm{v} / \mathrm{v})$ foetal calf serum (FCS) and $2 \mathrm{mM}$ glutamine, at $37^{\circ} \mathrm{C}$ in the presence of $5 \%(\mathrm{v} / \mathrm{v}) \mathrm{CO}_{2}$, and routinely passaged every $4-5 \mathrm{~d}$. For the adherence assays, the endothelial cells were seeded onto coverslips (13 $\mathrm{mm}$ diam.) in 24-well plates (Becton Dickinson) and grown to confluence. $C$. albicans ATCC 44808 and C. krusei DSM 70079 were grown overnight in Sabouraud medium at $30^{\circ} \mathrm{C}$, washed in cell culture medium and counted using a Neubauer haemocytometer. The viability of the cells was routinely inspected by trypan blue exclusion and consistently exceeded $99 \%$. Cells were diluted to a density of $10^{7}$ cells $\mathrm{ml}^{-1}$ and the C. albicans and C. krusei suspensions were mixed at equal concentrations. One-hundred microlitres of this mixed suspension $\left(5 \times 10^{5}\right.$ cells of each strain) were inoculated into the wells containing the endothelial cells and the plate was incubated for $4 \mathrm{~h}\left(37^{\circ} \mathrm{C}, 5 \% \mathrm{CO}_{2}\right)$ to allow adherence of the yeasts to the endothelial cells. Under these conditions (cell numbers of $5 \times 10^{5}$ per well and above, Ollert $e t$ al., 1993) the formation of germ tubes in C. albicans is repressed. After brief washing in PBS ( $\mathrm{pH} \mathrm{7 \cdot 2)}$ ) the cover slips were fixed and processed for in situ hybridization as described above.

Sequence analysis. For sequence comparisons, the PILEUP and FASTA programs of the Genetics Computer Group Wisconsin Package (Version 8, September 1994) were used.

\section{RESULTS}

\section{Selection of an oligonucleotide probe specific for $C$. albicans and C. tropicalis}

To establish the method of fluorescent in situ hybridization for the specific detection of different species of the genus Candida, we decided to use a probe which was directed against a target region in the $18 \mathrm{~S}$ rRNA which is identical in $C$. albicans and $C$. tropicalis but differs from those of 


C. albicans
C. tropicalis
C. viswanathii
C. maltosa
C. parapsilosis
D. hansenii
C. guilliermondii
H. polymorpha
C. kefyr
K. lactis
C. glabrata
S. cerevisiae
C. lusitaniae
A. fumigatus
C. krusei

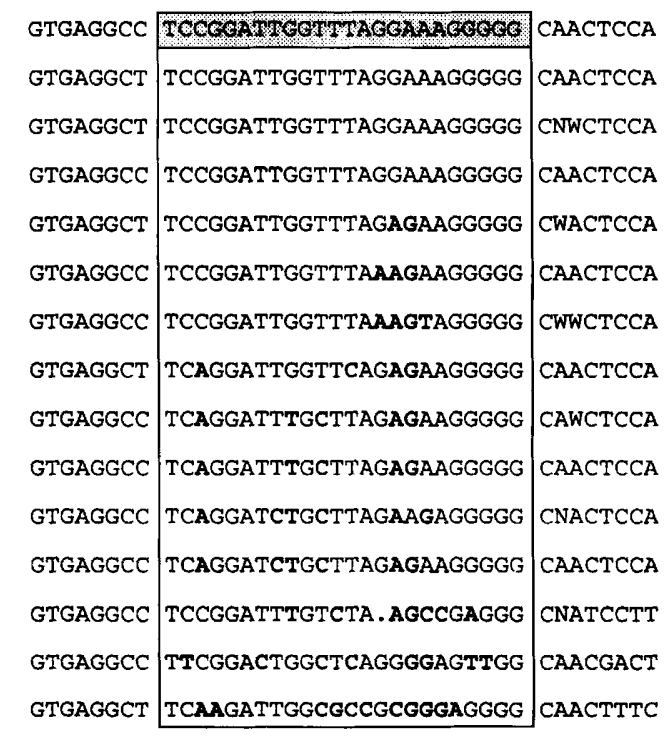

Fig. 1. Sequence alignment of the region in the ss rRNA genes of Candida spp. and other fungi corresponding to nucleotides 1666-1705 of the $S$. cerevisiae 18S rRNA. The target region of the oligonucleotide probe 020 from 1674 to 1697 is boxed; nucleotides different from the $C$. albicans sequence are shown in bold. The sequences were obtained from the EMBL data bank using the following accession numbers: $X 53497$ ( $C$. albicans), M55527 (C. tropicalis), M60309 (C. viswanathii), D14593 (C. maltosa), M60307 (C. parapsilosis), X62649 (Debaryomyces hansenii $=C$. famata), M60304 (C. guilliermondii), M60310 (Hansenula polymorpha), M60303 (C. kefyr), X51830 (Kluyveromyces lactis), M60311 (C. glabrata), M27607 (S. cerevisiae), M60306 (C. lusitaniae), M60301 (Aspergillus fumigatus). M60305 (C. krusei). W denotes A or T; $N$ denotes A, C, G or T.
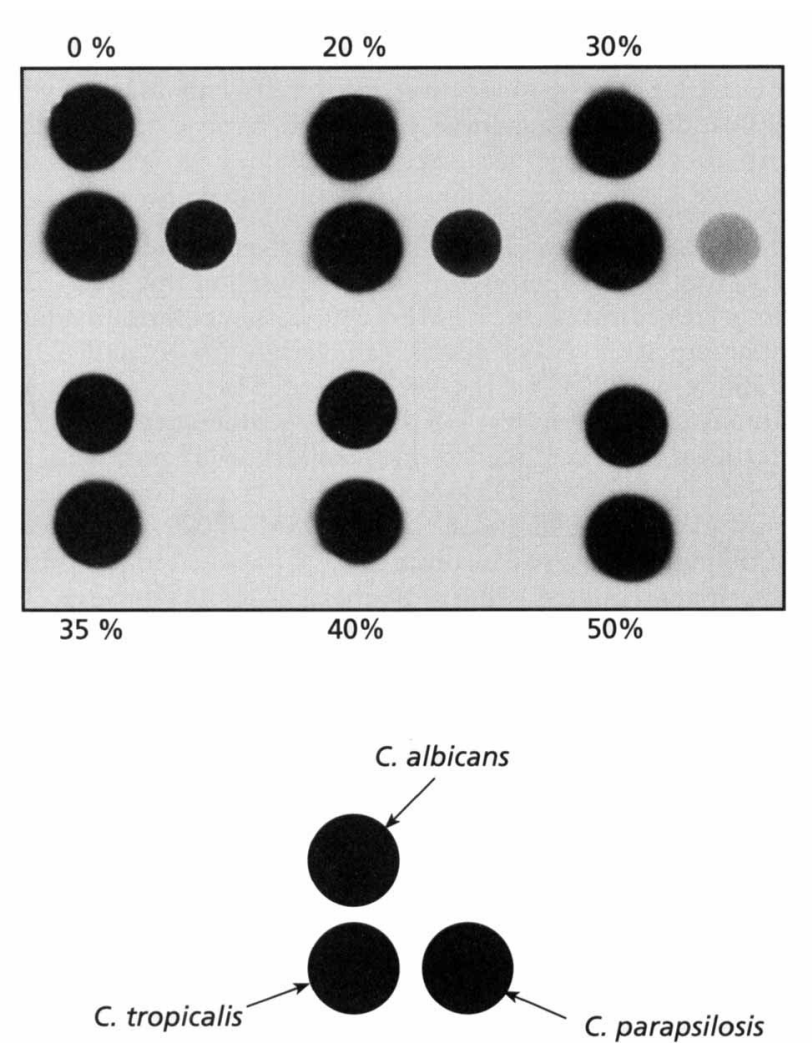

Fig. 2. RNA dot blot hybridizations using RNA from $C$. albicans ATCC 44807, C. tropicalis DSM 4238 and C. parapsilosis GR 34, and the digoxigenin-labelled oligonucleotide $\mathrm{O} 20$ as probe. Hybridizations were performed as described in Methods at a temperature of $51^{\circ} \mathrm{C}$ with the indicated formamide concentrations $(\%, v / v)$ in the hybridization buffer.

other pathogenic Candida species. Fig. 1 shows the alignment of a region in known $18 \mathrm{~S}$ rRNA sequences of Candida species and some other fungi corresponding to positions $1666-1705$ in the $S$. cerevisiae $18 \mathrm{~S}$ rRNA. This sequence is located in the variable region V9 of ss rRNAs (Neefs et al., 1993). A 24mer oligonucleotide named O20, complementary to positions 1674-1697 (see Methods and Fig. 1), was chosen as a probe because this region is identical in the two target species (and in the clinically irrelevant species $C$. viswanathii and $C$. maltosa), but different to various degrees in other medically important Candida species. Comparison of the selected target sequence with all accessible rRNA sequences in the data bank confirmed its uniqueness in the $18 \mathrm{~S}$ rRNA of the four species.

\section{Confirmation of probe specificity}

One of the advantages of oligonucleotide hybridizations is that by stringently controlling assay conditions, even sequences with only one nucleotide mismatch can be discriminated (Amann et al., 1990b). To establish suitable hybridization conditions for the specific detection of $C$. albicans and $C$. tropicalis, dot blot hybridizations with total RNA from these two organisms and the next related species, C. parapsilosis, which contains only two mismatches in the target region, were performed using the digoxigenin-labelled probe $\mathrm{O} 20$. Hybridization stringency was varied by changing the formamide content of the hybridization buffer. A hybridization temperature of $51{ }^{\circ} \mathrm{C}$ allowed the use of a wide range of formamide concentrations. At this temperature, a formamide concentration of $35 \%$ was found to be sufficient to distinguish C. albicans and C. tropicalis from C. parapsilosis (Fig. 2).

To confirm the ability of probe $\mathrm{O} 20$ to specifically detect $C$. albicans and $C$. tropicalis strains in general, dot blot experiments with RNA from a series of reference strains and clinical isolates of $C$. albicans, $C$. tropicalis, $C$. parapsilosis, C.glabrata, C. krusei, C. guilliermondii, C. kefyr, $C$. lusitaniae and $S$. cerevisiae (Table 1 ) were performed. A hybridization temperature of $43^{\circ} \mathrm{C}$ was used because this temperature was found to be suitable also for in situ hybridization (see below). The decrease in temperature 
(a)

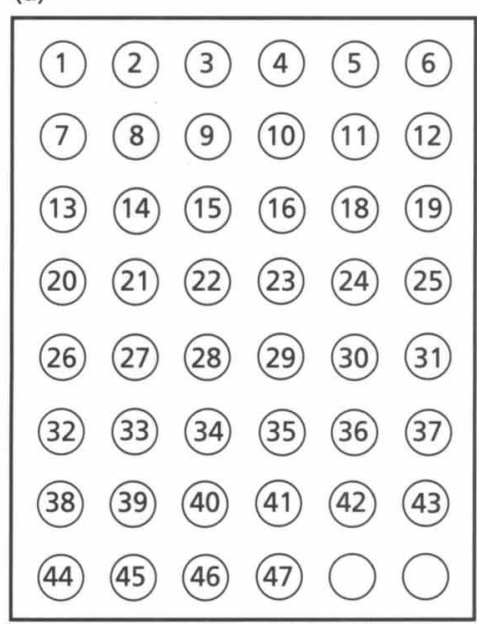

(b)

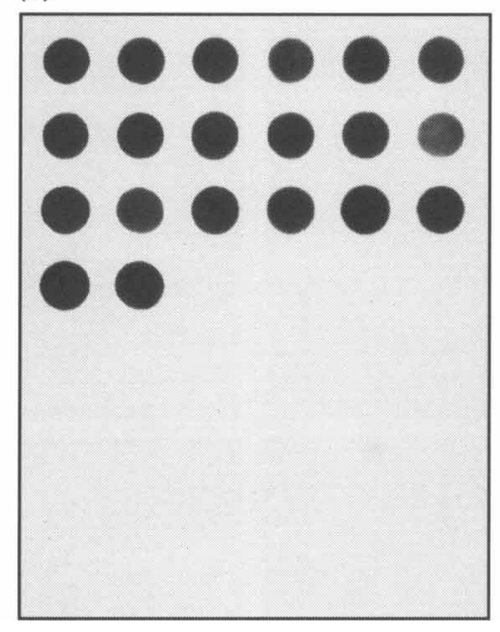

(c)

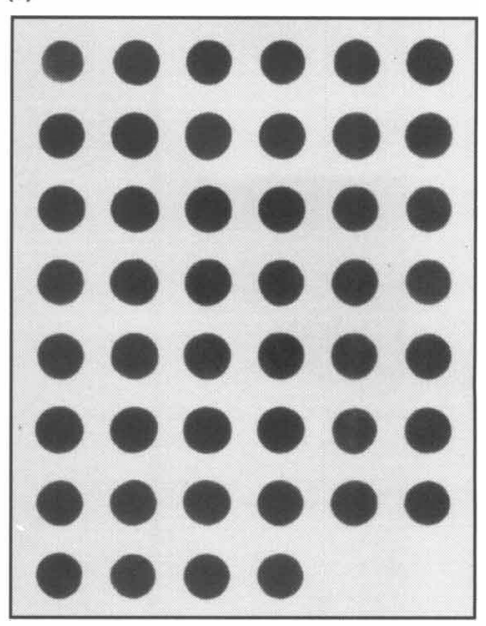

Fig. 3. RNA dot blot hybridizations using RNA from strains listed in Table 1 and the digoxigenin-labelled oligonucleotide $\mathrm{O} 20$ as probe. Hybridizations were performed as described in Methods at $43^{\circ} \mathrm{C}$ in a buffer containing $45 \%$ (probe $\mathrm{O} 20$ ) or $0 \%$ (probe EUK516) formamide. (a) Strain number (as in Table 1), (b) hybridization with probe O20, (c) hybridization with probe EUK516.

was compensated for by increasing the formamide concentration in the hybridization buffer to $45 \%$, resulting in comparable stringency conditions as determined in the previous experiment $\left(35 \%\right.$ formamide, $51{ }^{\circ} \mathrm{C}$, see Methods). The results confirmed the general applicability of probe $\mathrm{O} 20$ to distinguish $C$. albicans and $C$. tropicalis from other, even closely related, yeast species. All $16 C$. albicans and the four $C$. tropicalis isolates tested gave a positive signal, whereas no hybridization to RNA from other species was detected (Fig. 3b). In a control experiment, the filter was stripped and rehybridized with the oligonucleotide probe EUK516, which binds to RNA from all eukaryotic organisms, applying published stringency conditions (Amann et al., 1990a). Fig. 3(c) shows that all strains reacted with this probe, confirming that comparable amounts of RNA had been immobilized on the filter. These results demonstrated probe $\mathrm{O} 20$ to be suitable for the specific detection of the selected pathogenic target species C. albicans and C. tropicalis.

\section{Specific detection of C. albicans and C. tropicalis by fluorescent in situ hybridization}

To investigate if specific detection of both target species was also possible by fluorescent in situ hybridization, yeast cells of $C$. albicans and $C$. tropicalis and of two other Candida species having either a similar (C. parapsilosis) or a more divergent ( $C$. krusel) target sequence, were grown to exponential phase and processed for in situ hybridization with the FLUOS-labelled oligonucleotide O20 as described in Methods. All cells of $C$. albicans and $C$. tropicalis were brightly stained (Fig. $4 \mathrm{a}-\mathrm{d}$ ), whereas no fluorescence of C. parapsilosis and C. kruse $i$ was detectable (Fig. 4e-h). Thus, the difference of only two nucleotides in the target sequence of probe $\mathrm{O} 20$ in C.parapsilosis was sufficient to distinguish this organism from $C$. albicans and
C. tropicalis also in in situ hybridization experiments. To present additional evidence for this discrimination capacity, suspensions of the morphologically indistinguishable $C$. albicans and $C$. parapsilosis were mixed at different relative concentrations and hybridized to the FI.UOSlabelled probe O20 (Fig. 4i-o). Only a part of the cells seen in the phase contrast micrographs were labelled by the probe and the percentage of fluorescent cells in all cases corresponded well with the relative proportion of $C$. albicans cells in the mixtures. In some cases, a weak background fluorescence of $C$. parapsilosis cells was detected; however, this was not comparable with the specific staining of the $C$. albicans cells.

C. albicans does not only grow as a yeast but also in a mycelial form, which is often encountered in infected tissue. It was therefore investigated whether, in addition to blastoconidia, C. albicans hyphae can also be detected by in situ hybridization. The formation of germ tubes and hyphae in C. albicans A TCC 44808 was induced by growth in Soll's medium at $\mathrm{pH} 6.8$ and $37^{\circ} \mathrm{C}$ (see Methods). Following hybridization to the FLUOS-labelled probe O20, C. albicans germ tubes (Fig. 4p, q) and also longer hyphal elements (Fig. 4r, s) were efficiently labelled, although somewhat weaker than the mother blastoconidia, which is probably due to a reduced ribosome concentration in the vacuole-containing hyphae (Odds, 1988). The different cell wall of these morphological forms thus did not interfere with probe permeability.

\section{Specific detection of C. albicans in in vitro cell adhesion models}

Adherence of C. albicans to epithelial and endothelial cells is important for colonization as well as for invasion of the host tissue by the fungus (Calderone \& Braun, 1991; 

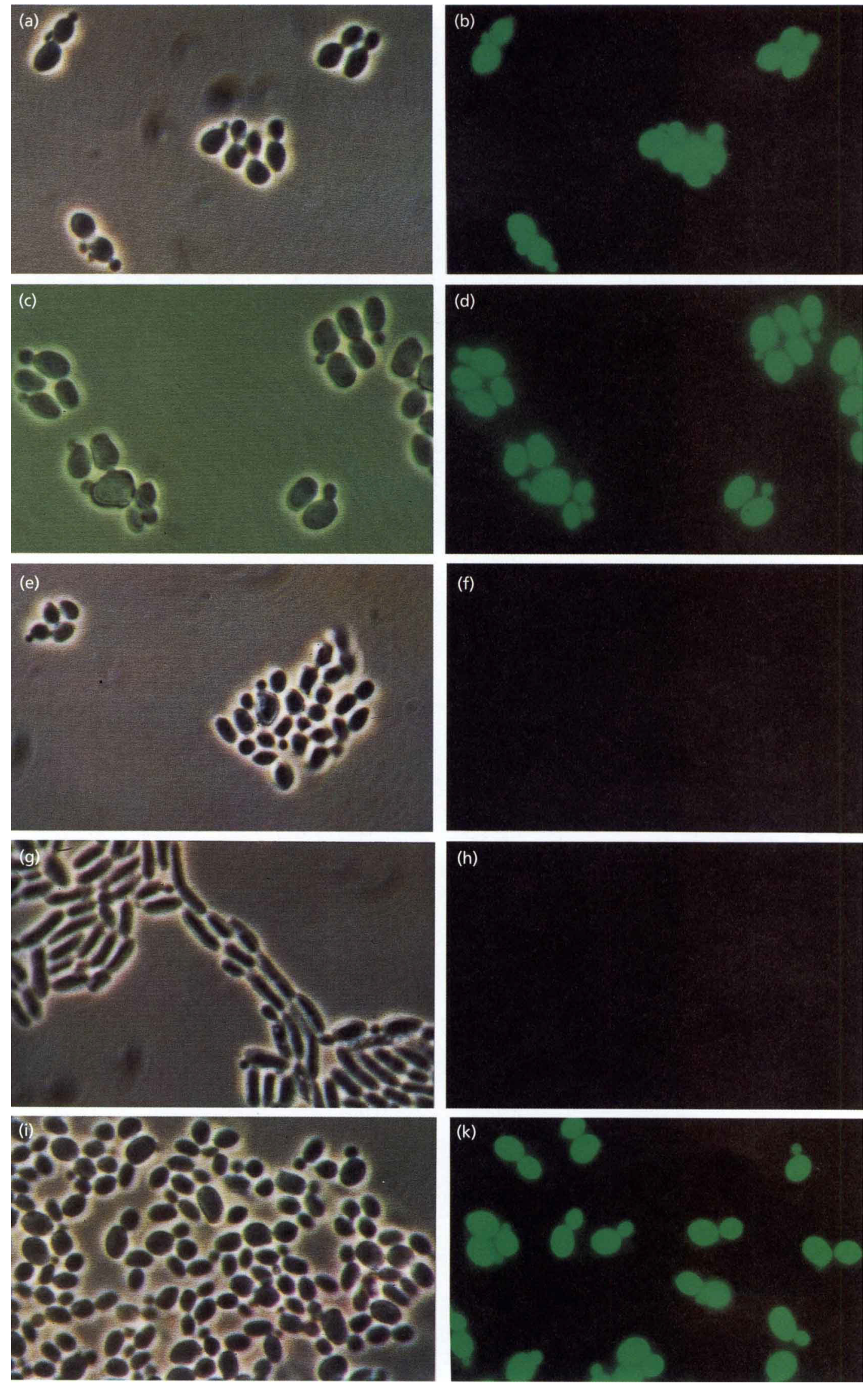

Fig. 4. For legend see facing page. 

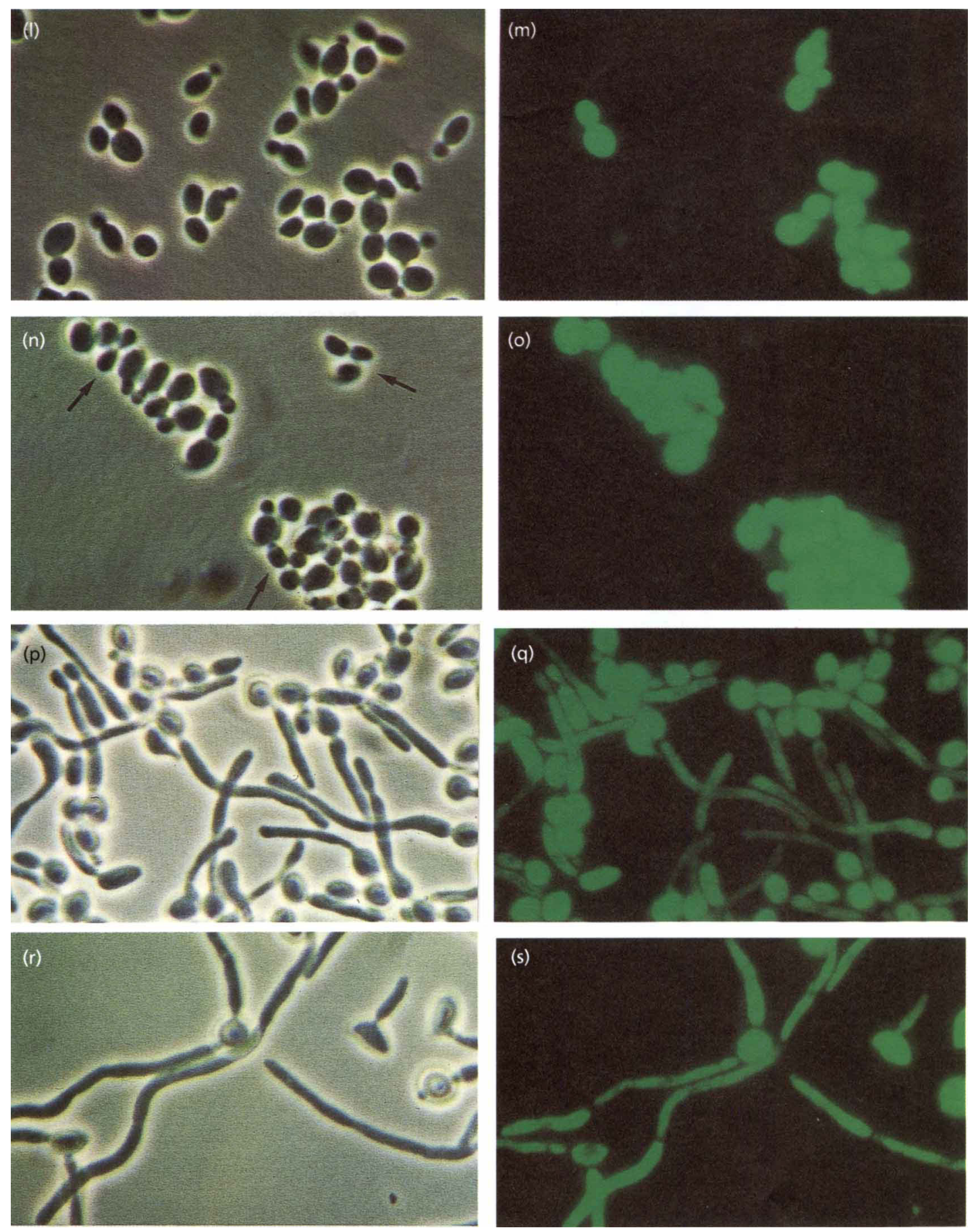

Fig. 4. Phase contrast $(a, c, e, g, i, l, n, p, r)$ and epifluorescence micrographs $(b, d, f, h, k, m, o, q, s)$ of $C$. albicans ATCC 44808 (a, b, p, q, r, s), C. tropicalis DSM 4238 (c, d), C. parapsilosis DSM 70126 (e, f), C. krusei DSM 70079 (g, h), and mixtures of C. albicans ATCC 44808 and $C$. parapsilosis DSM 70126 at a relative concentration of $1: 9(i, k), 1: 1(i, m)$ and 9:1 $(n, 0)$, respectively, after hybridization to the FLUOS-labelled probe 020 under stringent conditions (see text). The same section is shown in all respective phase contrast and fluorescence micrographs. In the phase contrast micrograph in $(n)$ the unlabelled C. parapsilosis cells are marked by arrows for better illustration. Detection of C. albicans ATCC 44808 germ tubes $(p, q)$ and elongated hyphae $(r, s)$ by probe $O 20$ is also demonstrated.

Hostetter, 1994). As adhesion to in vitro cultured cells is a widely used model system, human endothelial cells were infected with $C$. albicans and $C$. krusei to investigate if $C$. albicans can be differentiated from other Candida species by fluorescent in situ hybridization also on host cell surfaces. C. krusei was used as a control because the usually longer, 

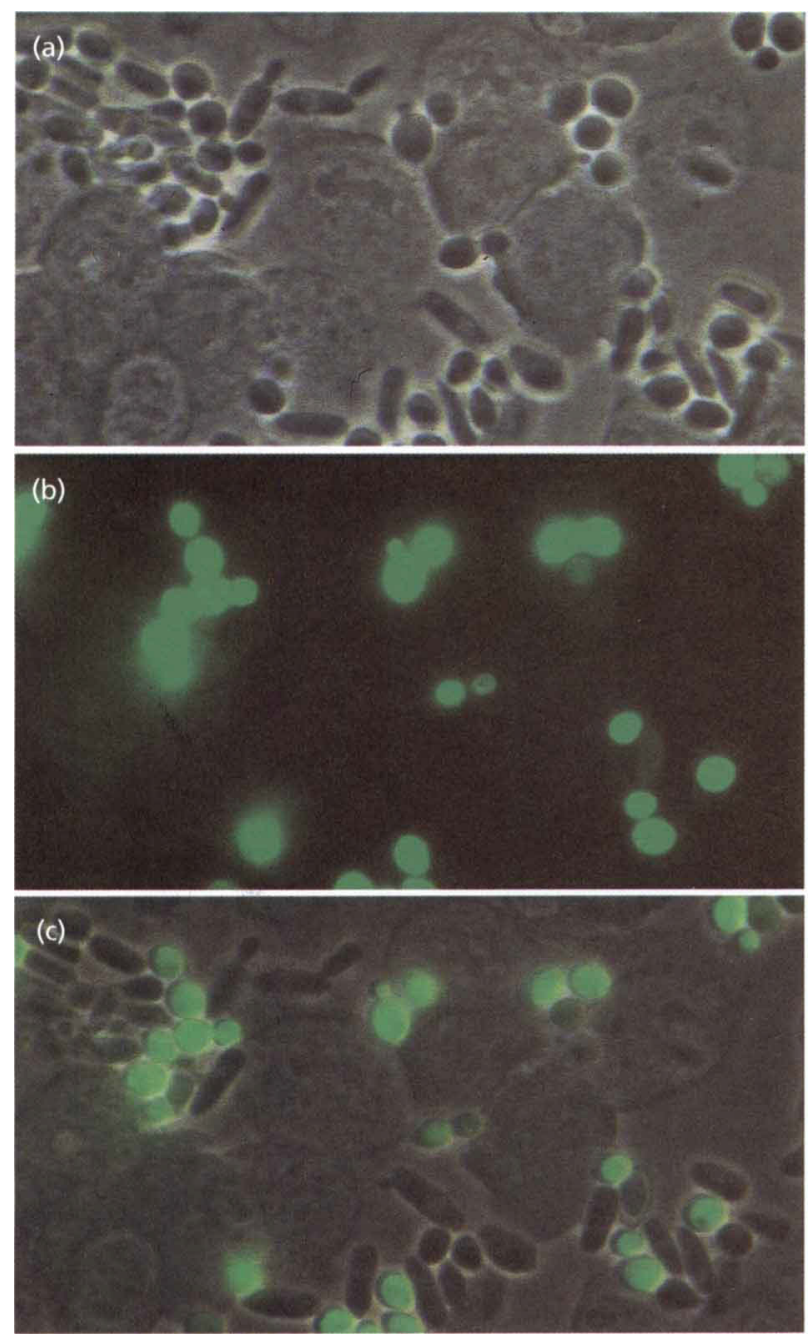

Fig. 5. Specific detection of $C$. albicans cells adhering to endothelial cells after infection of the human endothelial cell line EA.hy 926 with a mixture of C. albicans ATCC 44808 and C. krusei DSM 70079. For details see Methods. (a) Phase contrast micrograph showing the round $C$. albicans and the oval-shaped C. krusei adhering to the endothelial cell monolayer. (b) The same section viewed by epifluorescence microscopy. (c) Double exposure of the phase contrast and epifluorescence micrographs. Note that only the round $C$. albicans cells, but not the longer $C$. krusei cells are stained by the fluorescently labelled probe 020 .

oval-shaped cells (depending on their orientation) of this species could be morphologically distinguished from the round C. albicans blastoconidia. A confluent monolayer of the human endothelial cell line EA.hy 926 was incubated for $4 \mathrm{~h}$ with a mixture of $C$. albicans and C. krusei and, following removal of non-adherent cells by gentle washing, the sample was hybridized to the FLUOS-labelled probe O20. Fig. 5(a) shows the phase contrast micrograph of a section where cells from both Candida species adhere to the endothelial cells. Most of the cells with a round morphology were strongly labelled by the probe, whereas the oval-shaped cells were not stained (Fig. 5b). The discrimination between the two Candida species is also demonstrated in the double exposure of the phase contrast and the fluorescence micrograph in Fig. 5(c) where only the round $C$. albicans cells but not the longer C. krusei cells are fluorescent.

\section{DISCUSSION}

Identification of different species of the genus Candida is not possible by morphology alone but relies on cultivation of the organism and subsequent biochemical characterization. To detect and identify Candida species by microscopic examination, we have applied the method of fluorescent in situ hybridization using an $18 \mathrm{~S}$ rRNAtargeted oligonucleotide probe. As this method has so far not been used to our knowledge for the detection of Candida species, the aim of our study was to evaluate its general applicability for this group of pathogenic fungi. Therefore, a target site in the rRNA of the most important pathogen, $C$. albicans, which is identical in some additional Candida species but different in others, was selected. It would have been noticed if structural differences between species, e.g. differences in cell wall permeability, had affected successful detection in spite of a correct target sequence. On the other hand, the various degrees of differences in the target sequence in other species allowed the examination of the discrimination power of the probe. When using suitable hybridization conditions, C. albicans and $C$. tropicalis cells, which contain the selected target sequence, could be well discriminated from $C$. parapsilosis following hybridization with the fluorescently labelled probe $\mathrm{O} 20$, although the latter species contains only two nucleotide mismatches in the probe target region. This detection is likely to be specific for $C$. albicans and $C$. tropicalis isolates in general as all tested strains of both species reacted with the probe O20 in dot blot hybridizations, whereas no isolate of any other species gave a positive signal. The target sequence of our probe therefore seems to be conserved within the species. Two other Candida species, C. viswanathii and C. maltosa, also contain the identical target sequence, but hybridization of probe O20 to these organisms was not tested in this study as they are not clinically important (Kwon-Chung \& Bennett, 1992).

Probe $\mathrm{O} 20$ could also distinguish between $C$. albicans and $C$. krusei when a mixed population of both adhered to cultured endothelial cells. Although the adherence of the two species was not quantified in this assay, in situ hybridization appears to be a suitable method to study such phenomena in in vitro models with mixtures of different Candida species.

As a consequence of this study which has demonstrated rRNA-targeted oligonucleotide probes to be applicable for the specific detection of Candida species, our present investigations aim at the design of probes specific for single species and also of a probe that recognizes all clinically important members of the genus. Probe O20 is currently used to evaluate the described method for the detection of Candida in clinical material. Using a biotinylated, 5S rRNA-targeted oligonucleotide, Montone \& Litzky (1995) were able to detect Aspergillus hyphae 
and conidiospores in tissue specimens from patients with culture-proven aspergillosis. The direct detection by in situ hybridization would bring about a fast identification of the infecting organism, as the procedure takes less than a day, in contrast to methods requiring cultivation and phenotypic characterization. Even PCR protocols that rely on hybridization of the amplified product with a species-specific probe for species identification have been described to take $2 \mathrm{~d}$ (Jordan, 1994; van Deventer et al., 1995). Candida species other than C. albicans have been isolated with increasing frequency during the last few years and they differ in their susceptibility to antifungal agents (Wingard et al., 1991, 1993). C. krusei, for example, is reported to be intrinsically resistant to the widely used drug fluconazole (Vanden Bossche et al., 1994), and C. lusitaniae has been associated with amphotericin B resistance (Pfaller et al., 1994). A rapid identification of the infecting species would therefore facilitate the decision about appropriate treatment.

Many epidemiological studies have shown that in cases in which resistance to azoles occurs during therapy, $C$. albicans is often replaced by C. krusei or C. glabrata, species with higher resistance against these antifungals (for a recent review, see Rex et al., 1995). Most of the studies, however, described only single isolates from each episode, and it is not possible to decide if the newly detected resistant species came from an outside source or if it was already present during previous episodes. Examination of the clinical samples from patients infected with different Candida species by fluorescent in situ hybridization with probes of various specificities would yield information about the population structure. In addition, mixed infections by fungi and bacteria, e.g. C. albicans and Staphylococcus aureus or Enterococcus spp. (Rüchel et al., 1991) should be detectable by using differently labelled probes which are specific for the respective species.

In conclusion, the study demonstrated that in situ hybridization with fluorescently labelled, rRNA-targeted oligonucleotide probes is capable of specifically detecting and identifying Candida species. In future, the method may therefore be applied as a new diagnostic tool.

\section{ACKNOWLEDGEMENTS}

This study was supported by the Bundesministerium für Bildung, Wissenschaft, Forschung und Technologie (BMBF grant: O1 K1 8906-0) and the Fonds der Chemischen Industrie. We thank Prof. Hannelore Bernhard, Cornelia Heeg and Birgit Hoffmann for the identification and sending of Candida strains and Dr Gerwald Köhler and Dr Ingeborg Mühldorfer for critical reading of the manuscript. Sibylle Schadhauser is gratefully acknowledged for the preparation of the FLUOSlabelled probe $\mathrm{O} 20$.

\section{REFERENCES}

Amann, R. I., Binder, B. J., Olson, R. J., Chisholm, S. W., Devereux, R. \& Stahl, D. A. (1990a). Combination of $16 \mathrm{~S}$ rRNA-targeted oligonucleotide probes with flow cytometry for analyzing mixed microbial populations. Appl Environ Microbiol 56, 1919-1925.

Amann, R. I., Krumholz, L. \& Stahl, D. A. (1990b). Fluorescent- oligonucleotide probing of whole cells for determinative, phylogenetic, and environmental studies in microbiology. J Bacteriol 172, 762-770.

Amann, R. I., Springer, N., Ludwig, W., Görtz, H. D. \& Schleifer, K.-H. (1991). Identification in situ and phylogeny of uncultured bacterial endosymbionts. Nature 351, 161-164.

Amann, R. I., Ludwig, W. \& Schleifer, K.-H. (1995). Phylogenetic identification and in situ detection of individual microbial cells without cultivation. Microbiol Rev 59, 143-169.

Anaissie, E. (1992). Opportunistic mycoses in the immunocompromised host: experience at a cancer center and review. Clin Infect Dis 14 (Suppl. 1), 43-53.

Calderone, R. \& Braun, P. (1991). Adherence and receptor relationships of Candida albicans. Micrubiol Rev 55, 1-20.

DeLong, E. F., Wickham, G. S. \& Pace, N. R. (1989). Phylogenetic stains : ribosomal RNA-based probes for the identification of single microbial cells. Science 243, 1360-1363.

van Deventer, A. J. M., Goessens, W. H. F., van Belkum, A., van Vliet, H. J. A., van Etten, E. W. M. \& Verbrugh, H. A. (1995). Improved detection of Candida albicans by PCR in blood of neutropenic mice with systemic candidiasis. J Clin Microbiol 33, 625-628.

Edgell, C.-J. S., MCDonald, G. C. \& Graham, J. B. (1983). Permanent cell line expressing human factor VIII-telated antigen established by hybridization. Proc Natl Acad Sci US A 80, 3734-3737.

Fraser, V. J., Jones, M., Dunkel, J., Storfer, S., Medoff, G. \& Dunagan, W. C. (1992). Candidemia in a tertiary care hospital: epidemiology, risk factors and predictors of mortality. Clin Infect Dis 15, 415-421.

Golemis, E. A., Gyuris, J. \& Brent, R. (1993). Saccharomyces cerevisiae. In Current Protocols in Molecular Biology, Vol. 2, Chapter 13. Edited by F. M. Ausubel, R, Brent, R. E. Kingston, D. D. Moore, J. G. Seidman, J. A. Smith \& K. Struhl. New York: John Wiley \& Sons.

Hostetter, M. (1994). Adhesins and ligands involved in the interaction of Candida spp. with epithelial and endothelial surfaces. Clin Microbiol Rev 7, 29-42.

Jones, J. M. (1990). Laboratory diagnosis of invasive candidiasis. Clin Microbiol Rev 3, 32-45.

Jordan, J. A. (1994). PCR identification of four medically important Candida species by using a single primer pair. J Clin Microbiol 32, 2962-2967.

Kwon-Chung, K. J. \& Bennett, J. E. (1992). Candidiasis. In Medical Mycology, pp. 280-336. Philadelphia: Lea \& Febiger.

McConaughy, B. L., Laird, C. D. \& McCarthy, B. J. (1969). Nucleic acid reassociation in formamide. Biochemistry 8, 3289-3295.

Mankin, A. S., Skryabin, K. G. \& Rubtsov, P. M. (1986). Identification of ten additional nucleotides in the primary structure of yeast $18 \mathrm{~S}$ rRNA. Gene 44, 143-145.

Manz, W., Amann, R. I., Ludwig, W., Wagner, M. \& Schleifer, K.H. (1992). Phylogenetic oligodeoxynucleotide probes for the major subclasses of proteobacteria: problems and solutions. Syst Appl Microbiol 15, 593-600.

Montone, K. T. \& Litzky, L. A. (1995). Rapid method for detection of Aspergillus $5 \mathrm{~S}$ ribosomal RNA using a genus-specific oligonucleotide probe. Clin Microbiol Infect Dis 103, 48-51.

Neefs, J.-M., van de Peer, Y., de Rijk, P., Chapelle, S. \& de Wachter, R. (1993). Compilation of small ribosomal subunit RNA structures. Nucleic Acids Res 21, 3025-3049.

Odds, F. C. (1988). Candida and Candidosis. London: W. B. Saunders.

Ollert, M. W., Söhnchen, R., Korting, H. C., Ollert, U., Bräutigam, S. \& Brăutigam, W. (1993). Mechanisms of adherence of Candida 
albicans to cultured human epidermal keratinocytes. Infect Immun 61, 4560-4568.

Pfaller, M. A., Messer, S. A. \& Hollis, R. J. (1994). Strain delineation and antifungal susceptibilities of epidemiologically related and unrelated isolates of Candida lusitaniae. Diagn Microbiol Infect Dis 20, 127-133.

Poulsen, L. K., Lan, F., Kristensen, C. S., Hobolth, P., Molin, S. \& Krogfelt, K. A. (1994). Spacial distribution of Escherichia coli in the mouse large intestine inferred from $r$ RNA in situ hybridization. Infect Immun 62, 5191-5194.

Reiss, E. \& Morrison, C. J. (1993). Nonculture methods for diagnosis of disseminated Candidiasis. Clin Microbiol Rev 6, 311-323.

Rex, J. H., Rinaldi, M. G. \& Pfaller, M. A. (1995). Resistance of Candida species to fluconazole. Antimicrob Agents Chemother 39, 1-8. Rüchel, R., Borg-von Zepelin, M., Eiffert, H. \& Muche, R. (1991). Bacteria accompanying clinical Candida isolates from respiratory secretions and the genitourinary tract. Mycoses 34, 235-238.

Soll, D. R. (1986). The regulation of cellular differentiation in the dimorphic yeast Candida albicans. BioEssays 5, 5-11.
Vanden Bossche, H., Marichal, P. \& Odds, F. C. (1994). Molecular mechanisms of drug resistance in fungi. Trends Microbiol 2, 393-400.

Wagner, M., Erhart, R., Manz, W., Amann, R. I., Lemmer, H., Wedi, D. \& Schleifer, K.-H. (1994). Development of an rRNAtargeted oligonucleotide probe specific for the genus Acinetobacter and its application for in situ monitoring in activated sludge. $A p p l$ Environ Microbiol 60, 792-800.

Wilcox, J. N. (1993). Fundamental principles of in situ hybridization. J Histocbem Cytochem 41, 1725-1733.

Wingard, J. R., Merz, W. G., Rinaldi, M. G., Johnson, T. R., Karp, J. E. \& Saral, R. (1991). Increase in Candida krusei infection among patients with bone marrow transplantation and neutropenia treated prophylactically with fluconazole. N Engl J Med 325, 1274-1277.

Wingard, J. R., Merz, W. G., Rinaldi, M. G., Miller, C. B., Karp, J. E. \& Saral, R. (1993). Association of Torulopsis glabrata infections with fluconazole prophylaxis in neutropenic bone marrow transplant patients. Antimicrob Agents Chemother 37, 1847-1849.

Received 22 March 1996; accepted 5 July 1996. 